\title{
Diabetes Mellitus Patogenezinde Toxoplasma gondii'nin Rolü
}

\author{
Arş. Gör. Hasan YÜCEL, Doç. Dr. Emine KIR BiçER \\ Hatay Mustafa Kemal Üniversitesi, Sağlık Bilimleri Fakültesi, HATAY
}

\author{
DOI: http://dx.doi.org/10.29228/tjdn.56790
}

\section{Derleme}

Sorumlu Yazar

Hasan YÜCEL

Tel:05437626460

E-mail:

hsnyc101@gmail.com

\section{Hasan YÜCEL \\ ORCID: 0000-0001-9157-1594}

\section{Emine KIR BiÇER}

ORCID: 0000-0002-4773-9393

Geliş tarihi: 15.11.2021

Kabul tarihi: 29.12.2021

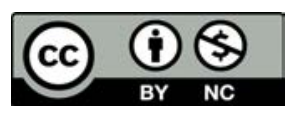

\section{Özet}

Toxoplasma gondii (T. gondii), dünya çapında önemli bir hastalığın etken parazitidir. Bu zorunlu hücre içi parazit, pankreas dahil olmak üzere herhangi bir çekirdekli hücreyi enfekte edebilir ve çoğalabilir. Insülin, pankreas tarafından salgılanan ve kan şekeri konsantrasyonunu kontrol etmekten sorumlu bir hormondur. Insülin üretiminin eksikliği, diabetes mellitus gelişiminde rol oynamaktadır. Diyabetes mellitus dünya çapında bir halk sağlığı sorunu olmaya devam etmektedir. Artan salgını açıklamak için obezite, fiziksel hareketsizlik ve diyet kalıpları gibi potansiyel nedenler öne sürülse de, tanımlanamayan çevresel belirleyiciler de olabilir. Yeni gelişen bu araştırma alanı bulaşıcı ve çevresel patojenlerin diyabetle ilişkisini incelemeye başlamaktadır. Özellikle bu patojenler düşük dereceli inflamasyona neden olarak tip 2 diyabet (T2DM) riskini ve gelişimini kolaylaştırır. Ancak bu teori üzerine yapılan çalışmalar halen yetersizdir. Bu derleme, T2DM'ye yol açan inflamasyon sürecinde T. gondii'nin rolüne ilişkin mevcut bilgileri ele almakta, T. gondii ve T2DM arasındaki ilişkiyi açıklayan mevcut çalışmaları incelemekte ve gelecekteki çalışmalar için T. gondii'nin T2DM üzerindeki rolünü belirlemek için önerilerde bulunmaktadır.

\section{Anahtar Sözcükler: Diabetes mellitus; Toxoplasma gondii; Etyoloji}

\section{Abstract}

Toxoplasma gondii (T. gondii) is the causative parasite of an important worldwide disease. This obligate intracellular parasite can infect and replicate inside any nucleated cells including those of pancreas. Insulin is a hormone secreted by the pancreas and is responsible for controlling blood glucose concentration. Deficiency of insulin production accounts for the occurrence of diabetes mellitus. Diabetes mellitus continues to be a major challenge for public health authorities worldwide. While potential causes such as obesity, physical inactivity, and dietary patterns have been proposed to explain the growing epidemic, there may also be unidentified environmental determinants. However, the studies on this theory are still insufficient. This review addresses the existing knowledge of the role of T. gondii in the inflammation process leading to T2DM, examines the current studies describing the relationship between T. gondii and T2DM, and makes recommendations for future studies to determine the role of T. gondii in the pathogenesis of T2DM.

\section{Keywords: Diabetes Mellitus; Toxoplasma gondii; Etiology}

\section{Giriş}

Diabetes Mellitus, pankreasın beta hücrelerinden salgılanan insülin hormonunun yetersizliği, yokluğu ve/veya eksikliği sonucu ortaya çıkan, hiperglisemi, karbonhidrat, protein ve yağ metabolizmasında bozukluklar, kapiller membran değişiklikleri ve hızlanmış ateroskleroz ile seyreden, makrovasküler ve mikrovasküler komplikasyonların geliştiği morbidite ve erken mortalite riski ile bakım maliyeti oldukça yüksek, kronik seyirli endokrin ve metabolik bir hastalıktır (Amerikan Diabetes Association[ADA], 2020). Diyabet dünya genelinde görülen en yaygın hastalıklar arasındadır. Uluslararası Diyabet Federasyonu (IDF) 2021 raporunda; dünyada 537 milyon diyabetli (20- 79 yaş) olduğu tahmin edilmekte olup, bu sayının 2030 
yılında 643 milyon, 2045 yılında 783 milyona ulaşacağını söylemektedir (International Diabetes Federation [IDF], 2021). Ülkemizde Türkiye Diyabet Epidemiyolojisi Projesi (TURDEP - II) verilerine göre, diyabet görülme sıklığı 20 yaş üstü grupta \% 13,7 olarak bildirilmiştir (Satman vd., 2013).

Diyabet ve glukoz metabolizmasının bozukluklarının tanı ve sınıflamasında Diyabet Tanı ve Sınıflamasında Uluslararası Uzmanlar Komitesi, Amerikan Diyabet Cemiyeti (ADA), Dünya Sağlık Örgütü (WHO) ve Uluslararası Diyabet Federasyonu (IDF) gibi uluslararası kuruluşlar tarafından çeşitli kriterler yayınlan-mış, ADA'nın 2014 yılında güncellenen kriterlerine göre diabe-tes mellitus dört klinik kategoride sınıflandırılmıştır. Bu kate-goriye göre bunlardan üçü (tip 1 diyabet (T1DM), tip 2 diyabet (T'DM) ve gestasyonel diabetes mellitus (GDM)) primer, diğeri (spesifik diyabet tipleri) ise, sekonder diyabet formları olarak bilinmektedir (İmamoğlu vd., 2015;TEMD 2020).

Uzmanlara göre, hem T1DM hem de T2DM diyabette çeşit-li genetik ve çevresel faktörler, $\beta$-hücre kütlesi ve fonksiyonunu azaltır. T1DM'lilerin birinci derece akrabalarının prospektif olarak izlendiği çalışmalarda iki veya daha fazla adacık otoantikorunun sürekli pozitif çıkmasının, klinik hiperglisemi ve diyabet gelişimini öngördüğü bilinmektedir. T1DM'de mutlak insülin eksikliği vardır. Hastaların \%90'ında otoimmün, \%10 kadarında ise non- otoimmün $\beta$ - hücre yıkımı söz konusudur. Genetik yatkınlığı (riskli doku grupları) bulunan kişilerde çevresel tetikleyici faktörlerin (virüsler, toksinler, emosyonel stres) etkisiyle otoimmünite tetiklenir ve ilerleyici $\beta$-hücre hasarı başlar. $\beta$-hücre rezervi $\% 80-90$ oranında azaldığı zaman klinik diyabet semp-tomları ortaya çıkar. T2DM etyolojisinde, hücre-r eseptör defektine bağlı olarak organizmanın ürettiği insülin kullanımında ortaya çıkan sorunlar nedeniyle glukozun hücre içinde kullanı-lamadığı insülin direnci, pankreasın kan glukoz düzeyine yanıt olarak yeteri kadar insülin salgılayamadığı insülin sekresyonun-da azalma ve gıda alımına cevap olarak gastrointestinal sistemdeki özel hücrelerden salınan ve insülin sekresyonunu stimüle eden inkretin hormonundaki yetersizlikler sayılabilir.

Bunların dışında; pankreas adacık hücrelerinden glukagon salınımının artması, lipolizin artması, glukoz geri emiliminin artması ve nörotransmitter disfonksiyonu da patofizyolojide rol oynar. Ek olarak son yıllarda pek çok çalışma bağırsak mikrobiyomunu tip 2 diyabet ve obezite gibi yaygın hastalıkların gelişimi ile ilişkilendirmiştir (TEMD, 2020). Bunun yanı sıra bazı insan vücuduna yerleşen parazitlerin de T2DM oluşumuna katkıda bulunduğuyla ilgili araştırmalar literatürde mevcuttur. Toxoplasma gondii (T. Gondii), insanlarda ve diğer sıcak kanlı hayvanlarda kozmopolit bir dağılım gösteren zorunlu hücre içi protozoon parazitidir. İnsanlara bulaşma, kediler tarafından çevreye saçılan T.gondii ookistlerinin yutulması veya enfekte hayvanların etlerinin yenmesi yoluyla gerçekleşir. Kronik hepa-tit B'li hastalar, toksoplazmoz gibi diğer bulaşıcı hastalıklara ya-kalanma riski altındadır ve malign neoplazmaları veya diabetes mellitusu olan hastalar, radyoterapi veya kemoterapinin neden olduğu immünosupresyon veya metabolik bozukluklar nedeniyle $\mathrm{T}$. gondii ile kolayca enfekte olurlar (Mehtap, Ozcelik, ve Ozpinar 2018; Shin vd., 2009). T. gondii ayrıca psikiyatrik hastalıklarla da ilişkilendirilmiştir (Özpınarvd., 2020)

Yapılan çalışmada, diyabetik gebe kadınlarda anti-T. gondii IgM ve IgG antikor prevalansının diyabetik olmayan kontrol gebe kadınlara göre anlamlı olarak daha yüksek olduğunu gös-termiştir(Saki, Shafieenia, ve Foroutan-Rad, 2016).
Başka bir çalışmada 200 diyabetik hasta (T2DM) üzerinde yapılan çalışma-da, hastaların \%53'ünde Toksoplazma IgG pozitifliği ve \%13'ünde Toksoplazma lgM pozitifliği saptanmıştır. Elde edilen sonuçlar toksoplazmoz ile T2DM arasındaki ilişkiyi gös-termiştir (Ozcelik, Alim ve Ozpinar, 2020). Diğer bir çalışmada diyabet hastalarında ve kontrol deneklerinde $T$. gondii serop-revalansı incelenmiş ve $T$. gondii enfeksiyonunun risk faktörleri ve olası bulaşma yolları belirlenmiştir. T1DM hastalarında $(\% 16,50)$ kontrol deneklerinden $(\% 11,50)$ anlamlı olarak daha yüksek T.gondii seroprevalansına sahip olduğu, T2DM has-taları $(\% 23,50)$ kontrol deneklerinden $(\% 11,75)$ anlamlı olarak daha yüksek T. gondii seroprevalansına sahip olduğu ve GDM hastaları (\% 21.25) kontrol deneklerinden (\%12.00) anlamlı ola-rak daha yüksek T. gondii seroprevalansına sahip olduğu sap-tanmıştır. Sonuç olarak T. gondii enfeksiyonu ile üç tip diabetes mellitus (T1DM, T2DM ve GDM) arasındaki ilişkinin serolojik kanıtı çalışma ile gösterilmiştir (Li vd., 2018).

Diyabet bağışıklık sistemini etkileyen hücresel ve sistemik bir hastalıktır. Bu nedenle diyabetik hastaların protean enfeksi-yonlara karşı duyarlılığı artmaktadır. Diyabetli kişilerde T. gondii enfeksiyonuna karşı spesifik antikorların varlığı ELISA yönte-mini kullanarak araştırılmıştır. Sonuçlar 205 diyabetik denekten $145^{\prime}$ inin (\%70.3) seropozitif olduğunu göstermiştir. Diyabet ve yarı pişmiş et tüketiminin toksoplazmoz olasılığını artırdığı saptanmıştır (Jafari Modrek vd., 2015).

T1DM bir grup hastada T. gondii seroprevalansını araştırmak için yapılan çalışmada T. gondii antikorları, 60 tip I diyabet hastası ve 60 kontrolde ELISA tekniği kullanılarak serolojik olarak test edilmiştir. Diyabetli hastalarda toksoplazmozun genel seroprevalansı \%45,0 olarak saptanmıştır. Az pişmiş et tüketimi, kedilerle temas ve toprakla temas ile T. gondii seroprevalansı (T. gondii enfeksiyonunun olası risk faktörleri) arasında anlamlı bir ilişki tespit edilmiştir (Khattab vd., 2019).

Son zamanlarda yapılan çalışmalarda Helicobacter pylori ve Coxsakie B4 virus gibi enfeksiyöz ajanların diyabet ile ilişkili bulunmaları T.gondii'nin de diyabet için muhtemel bir neden olabileceğini düşündürmüştür (Majidiani vd., 2016). Kore'de hastaneye başvuran 1265 kişi üzerinde yapılan çalışmada antiToxoplasma seropozitifliğinin diyabetle ilişkili olabileceği sonucuna varılmıştır (Shin vd., 2009). Avustralya'da yayımlanan derle-mede araştırmacılar "toksoplazmik tip 2 diyabet" adında yeni bir çalışma alanı önermişlerdir (Nosaka, Hunter ve Wang, 2016). Ülkemizde Karakullukçu ve arkadaşlarının araştırmasında diyabet hastalarındaki seropozitiflik oranı, diyabet olmayanlara göre istatistiksel olarak önemli düzeyde yüksektir. Ortaya çıkan bu ilişkinin mekanizmasının ileri çalışmalarla ortaya konulması gerekmektedir (Karakullukçu, 2021) .

T. gondii enfeksiyonu ile T2DM arasındaki olası ilişkiyi göstermek üzere birkaç vaka kontrol epidemiyolojik çalışma yayın-lanmıştır (Gokce vd., 2008; Saki vd., 2016; Shih vd., 2013; Siyadatpanah vd., 2013). Bu çalışmaların çoğu İran gibi daha az gelişmiş ülkelerde yapılmış ve araştırma sonuçları T. gondii enfeksiyonu ile T2DM arasında genel olarak pozitif bir ilişki olduğunu göstermiştir. Gökçe ve arkadaşlarının tip 2 diyabetli 807 hasta ile 250 sağlıklı kontrol grubu arasında anti-T.gondii seropozitiflik oranlarını IgG ve IgM ELISA kitlerini kullanarak yaptıkları çalışmada T2DM grubunda sağlıklı kontrol grubuna göre daha sık lgG antikorları bulunmuştur. T2DM'li hastaların 19 'unda (\%2.4) ve sadece dört kontrolde (\%1.6, P=0.3) IgM antikorları da bulunmuş, diyabet süresi ile T. gondii IgG seropozitifliği arasında çarpıcı bir ilişki gözlenmiştir (Gokce vd., 2008). 
T2DM, altta yatan bir subklinik inflamasyonla birlikte insülin direncine neden olan bozulmuş pankreas $\beta$-hücre fonksiyonu ile karakterize edilir. Birçok rapor, obezite ve insülin direncinin, IL-2, IL-6, IL-12, IFN-y ve TNF-a gibi yüksek dolaşımdaki inflamatuar sitokin seviyeleri ile ilişkili olduğunu ve diyabetteki metabolik anormalliklerin ortaya çıkma olasılığını artırdığını ileri sürmektedir. Akabinde T2DM'nin klinik ekspresyonuna yol açan bu uzun süreli düşük dereceli inflamasyona olası bir katkı, protozoan parazit T. gondii'dir (Nosaka vd., 2016).

Sonuç olarak; bağışıklık sistemi baskılanmış diyabetli hastalarda, bağışıklık sistemi normal olan bireylerde daha nadir görülen toksoplazmoz gibi fırsatçı infeksiyonlara daha sık rastlanmaktadır. Bu kişiler hem enfeksiyonlara daha yatkındır hem de daha önce geçirilmiş olan toksoplazmozun reaktivasyon riski bu hastalarda daha yüksektir. Bu nedenle; bu hastaların belirli periyotlarla $T$. gondii açısından değerlendirilmeleri, $T$. gondii enfeksiyonu ile T2DM arasında daha sağlam bir bağlantı sağlamak için ortaya çıkan bu ilişkinin mekanizmasının ileri çalışmalarla ortaya konulması önerilmektedir.

\section{Kaynaklar}

1. American Diabetes Association. (2020). Introduction: Standards of Medical Care in Diabetes-2020. Diabetes Care, 43(Suppl 1), S1-S2. doi:10.2337/dc20Sint. PMID: 31862741 . http://www.ncbi.nlm.nih.gov/pubmed/31862741 (Erişim Tarihi: 01.06.2021)

2. International Diabetes Federation. (2021). Diabetes Atlas. 10th edition, https://diabetesatlas.org/atlas/tenth-edition/ (Erişim tarihi: 21.11.2021)

3. Gokce, C., Yazar, S., Bayram, F., Gundogan, K., Yaman, O., \& Sahin, I. (2008) Anti-Toxoplasma gondii antibodies in type 2 diabetes. The National Medical Journal of India, 21(1), 51.

4. Türkiye Endokrinoloji ve Metabolizma Derneği (TEMD). Diabetes Mellitus ve Komplikasyonlarının Tanı, Tedavi ve İzlem Kılavuzu 2020. Ankara: TEMD Yayınları.

5. İmamoğlu, Ş., Satman, I., Akalın, S., Salman, S., \& Yılmaz, C. (2015). Geçmişten Gelecege Diabetes Mellitus: Ankara, Pelin Ofset Matbaacılık.

6. Jafari Modrek, M., Saravani, R., Mousavi, M., Salimi Khorashad, A., \& Piri, M (2015). Investigation of IgG and IgM antibodies against Toxoplasma gondii among diabetic patients. International Journal of Infection, 2(3).

7. Karakullukçu, S. (2021). Trabzon'da 20 Yaş ve Üzeri Bireylerde Toksoplazmoz Seroprevalansı. Mikrobiyol Bul, 55(2), 233-247.

8. Khattab, H. M., El Bassiouni, S. O., Abuelela, M. H. \& Abd Elsalam, D. O. (2019). Seroprevalence of Toxoplasma gondii among a group of Egyptian patients with type I diabetes mellitus. Bulletin of the National Research Centre, 43(1), $1-7$.

9. Li, Y.-X., Xin, H., Zhang, X.-Y., Wei, C.-Y., Duan, Y.-H., Wang, H.-F., \& Niu, H.-T. (2018). Toxoplasma gondii infection in diabetes mellitus patients in China: seroprevalence, risk factors, and case-control studies. BioMed research international, 2018.

10. Majidiani, H., Dalvand, S., Daryani, A., Galvan-Ramirez, M. d. I. L., \& Foroutan-Rad, M. (2016). Is chronic toxoplasmosis a risk factor for diabetes mellitus? A systematic review and meta-analysis of case-control studies. Brazilian Journal of Infectious Diseases, 20, 605-609.

11. Mehtap, A., Ozcelik, S., \& Ozpinar, N. (2018). Seroprevalence of Toxoplasma gondii in patients receiving cancer treatment. Cumhuriyet Medical Journal, 40(1), 19-24.

12. Nosaka, K., Hunter, M., \& Wang, W. (2016). The role of Toxoplasma gondii as a possible inflammatory agent in the pathogenesis of type 2 diabetes mellitus in humans. Family Medicine and Community Health, 4(4), 44-62.

13. Ozcelik, S., Alim, M., \& Ozpinar, N. (2020). Detection of Toxoplasma gondii in fection among diabetic patients in Turkey. Clinical Epidemiology and Global Health, 8(3), 899-902.

14. Özpınar, N., Özçelik, S., Yılmaz, N., Yelboğa, Z., \& Kaya, T. (2020). Seroprevalence of Toxoplasma gondii infection among psychiatric diseases. International refereed academic journal of sports, health and medical sciences, cilt.34, no.478117, ss.52-60.

15. Saki, J., Shafieenia, S., \& Foroutan-Rad, M. (2016). Seroprevalence of toxoplasmosis in diabetic pregnant women in southwestern of Iran. Journal of Parasitic Diseases, 40(4), 1586-1589.

16. Satman, I., Omer, B., Tutuncu, Y., Kalaca, S., Gedik, S., Dinccag, N., ... Canbaz, B. (2013). Twelve-year trends in the prevalence and risk factors of diabetes and prediabetes in Turkish adults. European Journal of Epidemiology, 28(2), 169-180.

17. Shih, Y.-L, Ho, K.-T., Tsao, C.-H, Chang, Y.-H, Shiau, M.-Y, Huang, C.-N. \& Yang, S.-C. (2013). Role of cyotkines in metabolism and type 2 diabetes mellitus. Int J Biomed Lab Sci, 2(1), 1-6.

18. Shin, D.-W, Cha, D-Y, Hua, Q. J, Cha, G.-H \& \& Lee, Y.-H. (2009). Seroprevalence of Toxoplasma gondii infection and characteristics of seropositive patients in general hospitals in Daejeon, Korea. The Korean Journal of Parasitology, $47(2), 125$
19. Siyadatpanah, A., Tabatabaie, F., Oormazdi, H., Meamar, A., Razmjou, E., Hadighi, R., \& Akhlaghi, L. (2013). Comparison of anti-Toxoplasma lgG and IgM antibodies determined by ELISA method in diabetic and non-diabetic individuals in west Mazandaran province, Iran, 2011-2012. Ann Biol Res, 4(6), 281-285. 